\title{
Interpreting Yuan Shao's Failure in the Romance of the Three Kingdoms from the Perspective of Heroic Psychology
}

\author{
Xianru-Zheng \\ (Longyan University, Fujian ,364000)
}

\begin{abstract}
A psychological interpretation of Yuan Shao in The Romance of the Three Kingdoms reveals that Yuan Shao does not possess the main psychological characteristics of a hero. This paper carries out an in-depth study of Yuan Shao's journey to his defeat and analyzes Yuan Shao from four aspects, namely, temperament, character, personality and moral character. Based on this, this paper puts forward a preliminary view of the five primary psychological traits of the hero, which echoes with the mental health education in the campus influenced by traditional culture.
\end{abstract}

\section{Introduction}

In The Romance of the Three Kingdoms, Yuan Shao is not considered as a hero. In Chapter 21, Cao Cao had a discussion with Liu Bei on who is the hero. Liu Bei said, "Well, Yuan Shao then. The highest offices of state have been held in his family for four generations, and his clients are many in the empire. He is firmly posted in Ji Prefecture, and he commands the services of many able people. Surely he is one." But Cao Cao replied, "A bully, but a coward. He is fond of grandiose schemes, but is devoid of decision. He makes for great things but grudges the necessary sacrifice. He loses sight of everything else in view of a little present advantage. He is not one." . What Liu Bei saw was the outside while Cao Cao looked directly at Yuan Shao's inside mentality. For Cao Cao, the then heroes were only two: Liu Bei and himself. Therefore, he believed that Yuan Shao would be defeated by Cao and Liu. However, the conclusion is not supported by dialectical analysis, so this paper analyzes the conclusion according to the book based on psychology.

\section{Yuan Shao's path to defeat}

\subsection{Prologue}

Yuan Shao's appeared in Chapter 3, in which he was involved in a battle with Dong Zhuo for abolition. As a result, Yuan Shao said goodbye to all the other officials and went to Ji Prefecture. Later, Dong Zhuo said to Yuan Shao, "Please forgive my rudeness" . At the same time, someone said to Dong Zhuo that the Yuan family has flourished for four generations, and has many clients in the empire... It is better to forgive him and make him a chief. In this way, he would be so grateful that we don't need to worry about him. . Another person said that Yuan Shao was fond of scheming, but failed to make a decision, making him a chief can win popular support . Therefrom, Yuan Shao's title shifted Capitan of the Army to Chief of Bohai County. Yuan Shao's disadvantage is obvious. What's worse, the word "grateful" shows his near-sightedness as he went to take his office as a chief immediately.

As he was appointed by Cao Cao, he gathered many talents and soldiers numbering 30,000 and left the Bohai Sea to meet with Cao. Cao said, "The highest offices of state have been held in Yuan's family for four generations and his clients are many in the empire. Such a descent of the renowned Prime Minister (in ancient China) of the Han Dynasty can be the leader of our union. Later on, Sun Jian lost $\mathrm{Zu}$ Mao during the battle against Dong Zhuo, he felt so sad that he sent people to inform Yuan Shao at midnight. Yuan was shocked, "I didn't expect Sun would be defeated by Hua Xiong!" Then, he gathered dukes or princes under an emperor to for discussion. To Liu Bei, he said, "I honor you not because you are a famous lord, but you are the descent of the emperor . Cao praised Yuan Shao's descent out of courtesy, but Yuan Shao really emphasized on that. The shock of knowing Sun's defeat can be regarded as the lack of courage.

The battle against Dong Zhuo continued. Cao Cao went to see Yuan Shao and said, "I didn't move at the beginning, why?" Shao Wei replied, "All the soldiers were tired, so it is useless to attack." ... At the time of life and death, the world would be determined by one battle." ... All the dukes and princes all said Cao Cao should not attack. Cao Cao became furious and said, "I cannot discuss with these people." Later, he drew about 10,000 soldiers to attack Dong Zhuo. The message here is: Yuan Shao was also among "these people"; the union agreement failed after Cao Cao's move. Yuan Shao's ability as a leader is just mediocre! This is also an

* Corresponding author: Xianru-Zheng, Associate Professor, E-mail: xsx2000@qq.com 
evidence for Yuan's lack of strength.

Later, when Sun Jian acquired the seal of the state and resigned Yuan Shao, Sun got furious, pulled out the sword, and was about to kill the sergeant. Shao also drew a sword, saying, "He is my soldier. How dare you." ... Sun immediately rode away. Yuan was furious and wrote a letter to Liu Biao, the office in Jinzhou, telling him to intercept Sun. Both princes were furious and both pulled swords. Sun aimed to kill the sergeant to show his disrespect while Yuan was incapable of letting Sun hand out the seal of the state and was only able to write a letter to ask others to intercept Sun. Yuan, the leader lost his control over the union again.

The next day, Cao Cao, who was defeated by Dong Zhuo, sighed, "I am still in doubt, and I have disappointed everyone. How shameful!" [14] Yuan and other officials were speechless. Cao thought all those people have their own affairs in mind, thus went to Yangzhou. Someone said to Liu Bei that Yuan Shao was incompetent and would change his mind. Yuan Shao, after all people have returned, led the troops to Guandong. In this way, the union for catching Dong Zhuo formed by eight princes failed. In the face of Cao's blame, Yuan was speechless. Yuan was not loyal and could not work sincerely with others, therefore, he could not achieve success as he went to Guandong himself for shelter. The leader lost his control for the third time.

A few days later after the dissolution of the alliance, Gongsun Zan wrote to Yuan Shao, "We attack Ji Prefecture together and divide the land." After Yuan acquired the land, Gongsun blamed him for treachery. But Yuan replied, "Han Fu is not a talent and is willing to give Ji Prefecture to me. What does it have to do with you?" Gongsun said, "I thought you were loyal and faithful, that's why I recommended you as the leader of the union. What you have done proves you are cruel and cold-blooded. How can you still have the face to live in the world?" Zhao Yun, an officer under the jurisdiction of Yuan Shao, went to Gongsun as he saw Yuan as a person with no heart for the emperor and people. Let us go back to Yuan Shao. When Yuan Shu was in Nanyang, he heard the news that Shao has acquired Ji Prefecture. So he sent people asking for 1000 horses, but Shao refused. Shu was angry, so the bond between the brothers broke since then. It can be seen that Yuan Shao's focuses are the land and the horse. He has no heart for the people, and that's why the two princes did not get along. The mind of Yuan Shao can be observed.

\subsection{Transition}

In the recruitment of talents, Xun Yu from Yingyin, Yingchuan, a former subordinate of Yuan Shao, went to Cao seeking shelter. Cao said, "Xun Yu is so important to me that he is like Zhang Liang to Liu Bang! I will make his Chief of the army." Let us go to Chapter 21, Cao Cao said, "Now heroes are the ones who cherish lofty designs in their bosoms and have plans to achieve them." So, how did Yuan Shao treat his talents? When Xuan De asked Zheng Xuanshu to write to Yuan Shao and discuss the issue of attacking Cao. The adviser Tian Fengqi said that they cannot attack Cao, while Shen Pei said it was easy to defeat Cao. Adviser Ju Shou said, "Victory is not always to the many. Cao Cao's discipline is excellent; his soldiers are brave and well drilled. He will not sit down quietly waiting to be surrounded as Gongsun Zan did. Now you abandon the intention to inform the Throne of our success, which I find a good plan, but you intend to send out an army without any valid excuse. Our lord should not do that." Guo Tu replied, "You are wrong. No expedition against Cao Cao can lack excuse. But if our master would take the chance now offering itself of coming into his own, he will accede to the request in the letter of Zheng Xuan and ally himself with Liu Bei for the destruction of Cao Cao." When the four advisers were arguing, Yuan Shao could not make up his mind. Suddenly, there came two others, Xu You and Xun Shen, and, seeing them, Yuan Shao said, "You two have wide experience, how would you decide?" Yuan Shao said, "A letter from Zheng Xuan the Chair has arrived, counseling me to support Liu Bei in attacking Cao Cao. Now am I to send an army or not send an army? "They both cried with one voice, "Send! Your armies are numerous enough and strong enough. You will destroy a traitor and help the dynasty." "Your words just express my desire," said Yuan Shao and thenceforward the discussion turned on the expedition."

The first four advisers have two opposing opinions, and Yuan Shao could not make up his mind; the latter two advisers hold the same opinion, Yuan Shao felt they express his desire. Two is greater than one, and the soldiers are sent! Yuan Shao sent the army partly because he was forced by Zheng Xuan to save his brother; it was just about following the crowd. He did this also because two is greater than one; it was all about following the crowd. Therefore, his intention of doing this was merely petty benefits. Let us compare this case with Cao's. After the Cao was informed the military attack, he smiled, "Although Chen Lin is good, but Yuan Shao is not." Cao Cao's adviser Xun Yu said, "Yuan Shao is useless, why bother?" Kong Rong, who came to persuade him, said, "The army of Shao is huge in amount but not united and his advisors hold opposite opinions, so there must be some internal conversion. Though he has a million soldiers, they are of no big use!" Kong Rong turned silent. Cao laughed and said, "You are right." Cao and his adviser posed a difficult problem to Yuan Shao's six advisers and the lobbyist. Sure enough, Yuan Shao did not want to attack. In this way, the martial arts of the generals and advisers of the two sides are clearly divided. Yuan Shao has been sentenced to defeat by the enemy in terms of wisdom.

Cao said, "Although Yuan Shao is strong, he has too many doubts and indecisions. He is not a threat!" Guo Jia said, "Shao acts slowly and was suspicious. His counselors are contradictory. We don't have to worry about him." Tian Feng, a loyal strategist said to Yuan Shao: "Now that Xuchang is empty and we have the righteous excuse to send our army; this is a rare opportunity. Please consider it." Shao said, "I also know that this is the best choice, but I am in a trance and afraid that there will be disadvantages. I am determined not to 
send troops." Yuan Shao lost the opportunity. When Cao Cao saw the official call to arms, he jumped from the bed in great joy. Although Yuan Shao also had a great joy, he was in a trance. From this, we can see the difference in their mind.

\subsection{Climax}

When Liu Bei was defeated by Cao and had to turn to Yuan Shao, and Guan Yu rescued Cao Cao, Ju Shou said, "Yan Liang was narrow-minded, although he is brave, he cannot take responsibility on his own." Shao said, "He is a good general of mine. You cannot predict him."... Shao was angry, shouting at Liu Bei, "Your brother killed my general. You must be involved in all this. There is no use keeping you here." He was about to kill Liu Bei. But Yuan Shao is a person who has no claim. After hearing what Liu Bei said, he accused Ju Shou of giving the wrong advice to kill good people. Ju Shou said no to Yuan Shao's idea of chasing Cao at the Yellow River because he thought it was the best to stay in Yanjin and send army in batches to cross the river in the future. Shao was angry, "Yuan Shao said, "That is always the way with you fellows, always delaying and taking the dash out of the army." Ju Shou sighed, "Superiors do not curb their ambitions; inferiors crave for achievements; things are undone. Eternal is the course of Yellow River, shall I change it? "Thereafter Ju Shou feigned illness and went no more to the council. Yuan Shao lost an advisor. Yuan Shao ordered Wen Chou to share his command with Liu Bei and gave Wen Chou command of the front guard of seventy thousand soldiers and Liu Bei command of the rear guard of thirty thousand soldiers. Guo Tu and Shen Pei met with Yuan Shao, and said, "It was Guan who killed Wen Chou." Liu Bei pretended he did not know it. Yuan Shao was furious, "How dare you!" ... Yuan Shao later said, "Liu Bei is right. You almost made me to blame the good." Yuan Shao was happy, thinking Guan was ten times better than Sheng Yanliang and Wenqiu. But he had not acquired Guan yet. Liu Bei painted the cake, and Yuan Shao ate it, which was really stupid. Later, Shao said, "Recently, Guan has left Cao,, wanting to come to Hebei; I will kill him for Xue Yanliang and Wen Chou!" Liu Bei said, "Illustrious Sir, you wished to employ him and so I sent for him. Now you threaten to put him to death. the two men he slew were but deer compared with such a tiger as he is. When you exchange a couple of deer for a tiger, you need not complain of the bargain." Yuan Shao said,"Really I like him, I was only joking. You can send another messenger for him and tell him to come soon." Yuan Shao was eating a cake painted by Liu in a good mood. Looking at Liu Bei's plan to remove the shell, Guo Tu admonished Shao. But Shao thought he was just too suspicious. Yuan Shao was furious seeing Liu Bei not returning, wanting to attack him. Guo Tu said that they should worry about Cao first. Shao listened to his words. This time, he seemed to have done something right.

When Chen Zhen had returned and related the events in the South Land and told of the honors that Cao Cao had obtained for Sun Quan in return for his support, Yuan
Shao was very wroth, and he set about preparing for an attack on Xuchang with a force of seven hundred thousand northern soldiers. However, when Yuan Shaoxing's soldiers and officers were marching ahead, Tian Feng wrote from the prison suggesting not moving. $\mathrm{Ju}$ Shou agreed. The result was Ju Shou was imprisoned. ... Xu Wei, an advisor of Yuan Shao, said, "If you do not take it today, you will suffer from it. ... Yuan Shao turned on $\mathrm{Xu}$ You angrily and said, "How can you have the face to stand before me and propose plans, you extortionate fellow? You and Cao Cao have old liking for each other, and he has bribed you to do his dirty work for him and help his base schemes. Now you want to betray my army. I ought to take off your head, but temporarily I will let your neck carry it away. Get out and never let me see you again." Another two advisers were lost ( $\mathrm{Ju}$ Shou was loyal and $\mathrm{Xu}$ Wei was greedy)! It is precisely: the weak wins because it thinks more; the strong loses because it thinks about less. Yuan Shao, very remorseful, said, "I did not hearken unto Tian Feng, and now my soldiers have been beaten and I was nearly lost. How can I return and look him in the face." When Feng Ji made his suggestions, Shao roared: "How dare he laugh at me, the blockhead? Assuredly he shall die." Tian Feng said, "Yuan is narrow and unforgiving. He will not consider my loyalty. I serve a master like him, how stupid am I!" He committed suicide in prison. Talents in Hebei were all lost, how can Yuan Shao achieve success? Yuan Shao did not know how to use the talents!

Shao was defeated and went back to Ji Prefecture. He was upset and ignored political affairs. Yuan Shao was undecided to discuss with the four people on the matter of nominating his successor. ... Cao's army came, and Yuan Shao had to flee. Shao spit blood from his mouth, saying, "“Many battles have I fought, and little did I think to be driven to this. Heaven is afflicting me. You had better return each to his own territory and swear to fight Cao Cao to the end." He blamed Heaven for his failure, so how can he fight Cao Cao to the end? When Yuan Shao heard that Yuan Shang was lost, he was so shocked that the old disease recurred. He vomited blood and fainted to the ground, and died in the end. Later generations wrote poems about him: As he is famous and self-satisfied with three thousand subordinates under his command and millions of soldiers. He is a lamb with the skin of a tiger, and a chicken with the appearance of a phoenix. Two brothers cannot extend their family. Such as person is doomed because of his essence, but not because of Heaven!

So what about the two brothers? Wang Xiu said, "Brothers are as one's limbs. How can you possibly succeed if at a moment of conflict with an enemy you cut off one of your hands? If you abandon your brother and sever relationship, whom will you take in all the world as a relation? That fellow Guo $\mathrm{Tu}$ is a dangerous mischief-maker, who would sow dissension between brothers for a momentary advantage, and I beg you to shut your ears and not listen to his persuasions." Tan was angry and asked Wang Xiu to leave. How short-sighted the two brothers were! 


\subsection{Ending}

Since Cao has settled in Ji Prefecture, he went to Yuan Shao's tomb to set up a sacrifice. He said, "Not long ago when Yuan Shao and I worked together in military matters, he asked me, saying, 'If this disturbance does not cease, what fronts should be held?' And I replied asking him what he thought. He said, 'In the North of Yellow River, to the south I would hold the Yellow River on the north, guard against Yan and Dai* and absorb the hordes from the Gobi Desert. Thence southward I would try for the empire, and do you not think I might succeed?" I replied saying, "I depend upon the wisdom and force of the world directed by scholars; then every thing would be possible. These words seem as if spoken only yesterday, and now he is gone. Thinking over it I cannot refrain from tears." The level of and differences between Cao and Yuan are obviously set!

\section{Mental reasons for Yuan Shao's failure}

The battle of Guandu is the decisive battle of Yuan Shao's failure. From the general strength of both sides, Cao was weak while Yuan was strong, so Yuan was more likely to win. A key to transform general strength into specific strength is integration. However, Shao's army was not integrated" (Xun Yu's words). The reason for the lack of integration is that Yuan Shao is a person of no opinion. He is unforgiving and narrow; he is unconstrained, timid, ruthless, and has a strong desire for petty profits. Cao, Shao's rival is one of the greatest intelligent in the world. The two are not at one level at all.

\subsection{Temperament: insufficient courage to make decisions}

The Eastern Han Dynasty promoted talents by recommendation, which is the original form of the ninth-class official system. Recommendation requires someone to observe, so who? Naturally, it was the bureaucracy at the office who observed and recommended talents, and talents in a good family were observed. It should be noted that it is an improvement over the hereditary system because it adds the element of "inspection". Inspection is subjective to objective human activities. The standard of it is based on the merits required by the authorities and what the talents did. Liu Bei who was born in a low profile thought the illustrious family, plus the land of Ji Prefecture with so many subordinates and substantial soldiers and forage make Yuan Shao a candidate of hero. At the beginning of The Romance, Yuan Shao was elected as the leader of the union. Yuan Shao respected Liu Bei for he was a descent of the emperor, rather than his title. Therefore, the talents recommended at that time were from the hereditary family circle with big names, which limits the quantity and quality of the talents recommendation. Cao Cao's later talent policy broke through the scope and enhanced and quality of recommendation. Therefore, he was able to leverage all the intelligence of the world and can achieve everything.

Yuan Shu, Yuan Shao's brother who was sufficient in soldiers and forage claimed himself to be emperor and died in the end. Cao Cao established his overlord position by holding Han Emperor Xian. Yuan Shao was advantageous geographically and aimed to expand to the south. But in terms of the knowledge and courage, Yuan Shao lagged behind. He said goodbye to Dong Zhuo and asked others to intercept Sun Jian. He refused to give horses to his brother and wanted to attack Liu Bei out of anger. In the end, he vomited blood as he was defeated by Cao. Such a timid, narrow, irritable person is doomed to lose. Similarly, Zhou Yu blamed himself, sighing "Since the Heaven made Zhou Yu, why did he also make Zhuge Liang?", and he eventually vomited blood and died. Therefore, Yuan Shao ended up in failure with his own nature as a timid lamb and the appearance of a tiger.

As for adopting a relative's son as the heir for succession of family line, Yuan Shao's knowledge is also insufficient. Tian Feng said he was stupid to serve a master like Yuan Shao. It is even more stupid to use his talent improperly. After the death of Tian Feng, Yuan Shao went back to Ji Prefecture, upset and disregarded the political affairs. In this case, his wife Liu tried to persuade him to adopta relative's son as the heir for succession. Yuan Shang, the third son of his second wife Liu, was born with a handsome appearance. Yuan liked him very much and kept him around. After the defeat, Liu persuaded him to adopt Yuan Shang, but after negotiating with the new four-member think-tank, he could not make up his mind. ... After vomiting blood, Yuan Saho fainted to the ground. Mrs. Liu panicked into the bedroom. Shao can't speak but able to move his fingers. Liu asked whether Shang can be the successor. Shao nodded. Later he wrote a will on the bed. Such a big intelligent decision is made when he was in bad condition. Although Yuan Shao discussed with the four advisors, they could not achieve consensus. He preferred the appearance of his third son and his second wife, that's part of the reasons for his decision. Yuan Shao was governed by his emotion, but not reason, thus he was influenced by the advisors of the third son. The ability to recognize and distinguish is one of the key components of a hero, but Yuan Shao did not have it.

\subsection{Character: suspicious, unable to remember the loyalty of his subordinates}

Character consists of an intrinsic attitude and an external acting style, and is reflected in various activities or events of one treating himself/herself, other person, and things. If Yuan could properly absorb the wisdom of the advisors and leverage their strength, he could be strong in intelligence. The problem is that although he had a broad-minded appearance, Yuan Shao was suspicious and unable to remember the loyalty of his subordinates. When the four advisers were arguing over the attacking issue, he could not make a decision. It was when $\mathrm{Xu}$ You and Xun Chen strongly support the idea of sending troops that Yuan Shao made his decision. To attack or not is a big decision to make. Yuan should not be influenced 
by other advisors. Later, he made Shen Pei the chief commander. Xu Wei was dissatisfied and Ju Shou was also unhappy for his talent was not fully used. Therefore, he did not plan to make progress. Yuan Shao, on the other hand, was so suspicious that he did not make military moves. From Yuan Shao's mentality and his relationship with the advisors, Cao saw that "Yuan Shao is slow in action and suspicious, why worry!" Guo Jia, Cao Cao's advisor also saw that "Shao's nature was slow and suspicious, and his advisors are contradictory to each other. He is not a threat." What's worse, Yuan Shao failed to remember the loyalty of his subordinates, causing Tian Fen's suicide, Ju Shou's imprisonment, Xu Wei's leave, Xin Pei's betrayal, Shen Pei's death, and Guo Tu and Feng Ji's slander and misuse, ect. Loyalty is the traditional virtue of the officials to the monarch and the scholars to the master. It is also a platform for the officials and scholars to exert their wisdom and for the king and a stage for the master to enlarge wisdom. When the platform and the stage collapse, wisdom and strategy lose their powerful support. This is a big mistake.

\subsection{Personality: indecisive and timid}

Beyond moral elements, personality is stable and unique qualities, and a consistent and continuous self. Two of Yuan Shao's most outstanding personalities are indecisiveness and timidity. He is good at scheming, which is a positive trait. If he was decisive enough, he could have a great mind. Unfortunately, Yuan Shao is indecisive. He would hesitate and stagnate in the event of a major incident, thus he often lost opportunities. Yuan Shao's lack of decisiveness in the Battle of Guandu and the adopting issue ultimately put him in a disadvantageous position. That's why he was defeated by Cao Cao and himself. Making decisions is a real-time test of decision-making ability in a complicated and confusing context. Courage and insight is the key to correct decisions. Unfortunately, Yuan Shao is inferior in this respect and is therefore defeated by Cao. On the issue of setting the heir, Yuan Shao was also blind because of his mind and emotions. In the end, he cut up all the mental complications by pointing when he was in confusion.

A kind and pleasant countenance is outward appearance of inner peace. In order to achieve that, one needs to have a strong mind, high ambitions and great courage. Yuan Shao lagged behind in these aspects. His family background did not equip him with courage and a strong mind, as can been seen from his reactions to various occasion in his life. He was often shocked and angry, but less happy and satisfied (most empty happiness). For example, "Guan is ten times better than Yan Liang and Wen Chou." According to rough calculation, he was shocked and angry for nearly 20 times. People with courage are not easy to be shocked or get angry. How can a person like Yuan Shao defeat Cao, who "I would rather to let down world, but not let down by the world."
When he was about to do something big, he tended to be afraid of death, which is a reflection of timidity; when he was about to do something small, he tended to wildly pursue petty profits, which is a discard of the fundamental righteousness. People who do great things are loyal to the righteousness. But Yuan Shao is not one! What he wanted was the state seal, the land, the horses, and so-called righteousness of the letter hidden in the clothes. Just like Cao laughed, "they have the literary gift; they would rather have the military too to back it up. This fellow may be a very elegant writer, but what if Yuan Shao's fighting capacity falls short?" With such moral characters, how far Yuan Shao can go?!

\section{Hero's psychological traits}

In the eyes of Cao Cao, Yuan Shao is not a hero, even worse than $\mathrm{Lv} \mathrm{Bu}$. What is the hero? According to Cao, the dragon among animals compares with the hero among people; heroes are the ones who cherish lofty designs in their bosoms and have plans to achieve them. Cao Cao also gave an example, bluntly pointing out that the heroes in the world are Liu Bei and himself. In this definition, ambition, designs, and plans are the three traits of a hero. There are many people with great ambitions and designs, but Cao Cao and Liu Bei were the only two had their plans as well. The plan is the way to achieve the ambition and design, while ambition can be governed by self. People who can achieve that must have sufficient courage and a number of advisors working in harmony yet diversity.

It is fair to say that in the Romance of the Three Kingdoms, only Cao Cao and Liu Bei can be regarded as true heroes. As for Sun Quan, just as Cao Cao said, one would be blessed to have a descent like Sun. So, Sun was greatly benefited from his father and brother. Heroes have the wisdom to make 1 out of zero, great ambitions, superhuman courage, ability to control the situation, and the wisdom to read the advisors. These five traits are the primary psychological characteristics of the hero.

\section{Annotation:}

There are many versions of The Three Kingdoms. The original texts of The Three Kingdoms used in this article are all from version of The Four Greatest Chinese Famous Ancient Books (The Three Kingdoms, Water Margin, Journey to the West, Dream of the Red Mansion) (volume 1), which is published by Hainan Publishing House in 1998. Some citations are difficult to list one by one, and I apologize for it.

\section{References:}

The Four Greatest Chinese Famous Ancient Books (The Three Kingdoms, Water Margin, Journey to the West, Dream of the Red Mansion), Haikou,Hainan Publishing House, 1998 